\title{
The Challenge of Adolescent Crowd Research: Defining the Crowd
}

Jennifer Riedl Cross

College of William and Mary, jrcross@wm.edu

Kathryn L. Fletcher

Follow this and additional works at: https://scholarworks.wm.edu/educationpubs

Part of the Gifted Education Commons

\section{Recommended Citation}

Cross, Jennifer Riedl and Fletcher, Kathryn L., The Challenge of Adolescent Crowd Research: Defining the Crowd (2009). Journal of Youth and Adolescence, 38(6), 747-764.

https://doi.org/10.1007/s10964-008-9307-6

This Article is brought to you for free and open access by the School of Education at W\&M ScholarWorks. It has been accepted for inclusion in School of Education Articles by an authorized administrator of W\&M ScholarWorks. For more information, please contact scholarworks@wm.edu. 
RUNNING HEAD: Challenge of Crowd Research

The Challenge of Adolescent Crowd Research: Defining the Crowd

Jennifer Riedl Cross

01jrcross@bsu.edu

Kathryn L. Fletcher

klfletcher@bsu.edu

Ball State University

Department of Educational Psychology TC 524

2000 W. University Avenue

Muncie, IN 47306

(765) $285-8500$

Final version accepted for publication

Cross, J. R., \& Fletcher, K. L. (2009). The challenge of adolescent crowd research: Defining the crowd. Journal of Youth and Adolescence, 38(6), 747-764. doi: 10.1007/s10964-0089307-6 


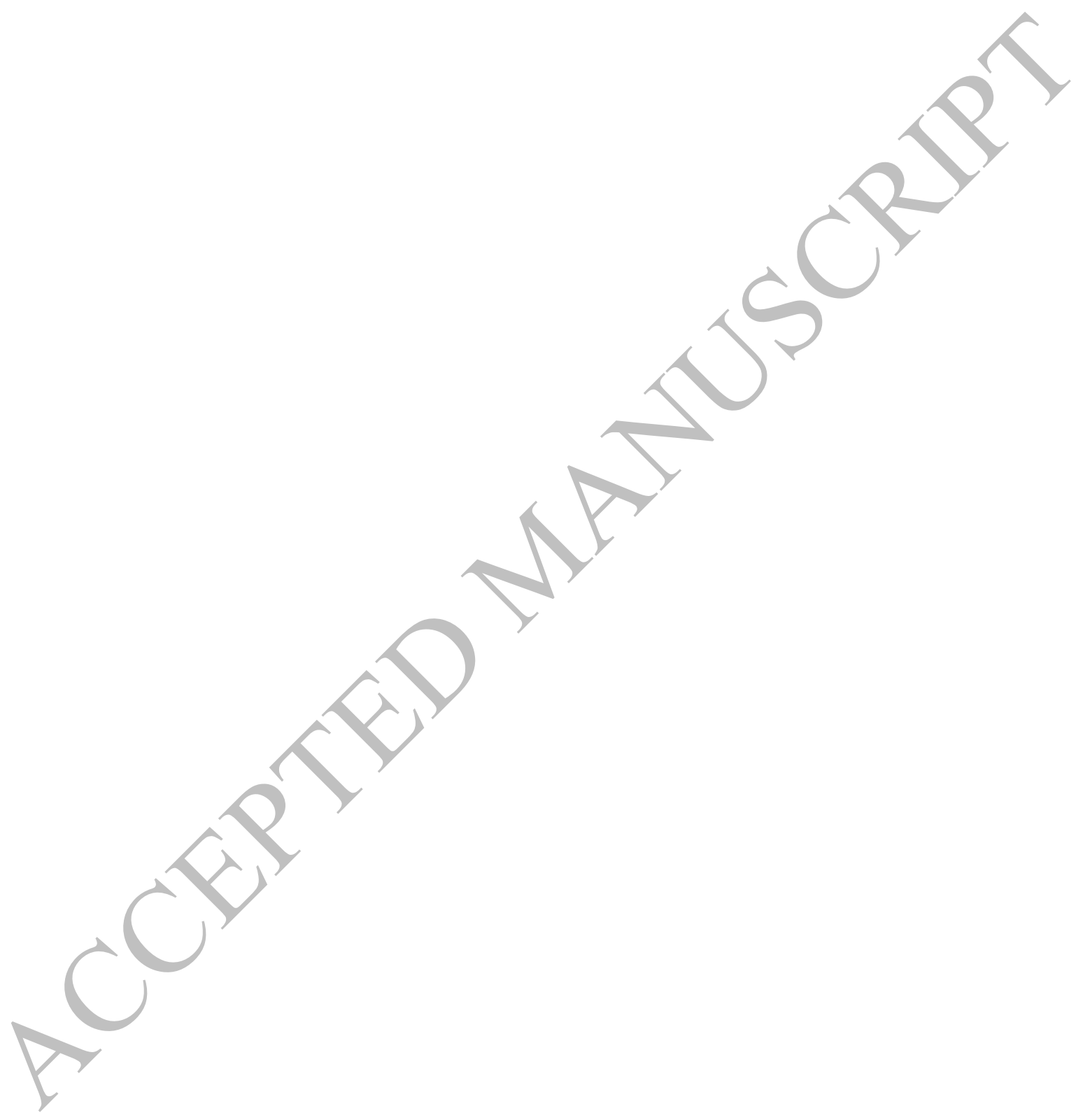




\begin{abstract}
As research on adolescent crowds has increased over the past several decades, researchers appear to be confident in their claims of the consequences of crowd membership, even suggesting targeted interventions. This review of the various methods used to identify adolescents' crowd membership suggests that this confidence may be misplaced. There are diverse methodologies used in this research area that examine different samples of adolescents belonging to each crowd. Social-type rating methods, self-identification methods, grouping by adolescent behaviors or characteristics, and ethnographic or other qualitative methods should be accompanied by greater specificity in terminology to alert researchers to the various phenomena being studied (i.e., "reputational crowd," "interactional crowd," "behavioral crowd," "affiliation crowd"). Additionally, studies comparing the various self-identification approaches and peer ratings are needed, along with reliability studies of peer ratings. More attention to specific methodology to determine crowd membership and its stability will aid the design of theoretical models of adolescent crowds and contribute to developmental outcome research.
\end{abstract}


The Challenge of Adolescent Crowd Research: Defining the Crowd

In his 1942 study of adolescents in Elmtown, Hollingshead (1975) had students classify their peers into "reputational categories" based on their reputation "in the student group" (p. 164). His subjects could readily do this, creating three categories: the Elites, the Good Kids, and the Grubby Gang. There is substantial evidence, both anecdotal and empirical, that the phenomenon of adolescents categorizing their peers in similar fashion exists in secondary schools (e.g., Brown \& Lohr, 1987; Downs \& Rose, 1991; Kinney, 1990; Schwendinger \& Schwendinger, 1985). Hollingshead's study ushered in a new era of research on this social phenomenon that has come to be known as the adolescent crowd.

Researchers have concluded that adolescents in different crowds vary in their health-risk behaviors (Dolcini \& Adler, 1994); drug use and preference for violence (Sussman, Dent, \& McCullar, 2000); psychological adjustment (Barber, Eccles, \& Stone, 2001; Heaven, Ciarrochi, Vialle, 2008); influence and application of peer pressure (Clasen \& Brown, 1985); academic achievement orientation (Brown, Lamborn, Mounts, \& Steinberg, 1993; Heaven, Ciarrochi, Vialle, 2008); and their behaviors and characteristics (e.g., Heaven, Ciarrochi, Vialle \& Cechavicuite 2005; Stone \& Brown, 1998; Strouse, 1999). As such, crowds are an important aspect of adolescent life and membership in a crowd may have significant implications for an adolescent's psychological and physical health. Delsing, ter Bogt, Engels and Meeus (2007) found significant correlations between crowd affiliation and depression, anxiety, delinquency and aggression. In their review of 44 studies on "adolescent peer group identification," Sussman, Pokhrel, Ashmore, and Brown (2007) report common findings of a relationship between "Deviant" peer group membership and increased drug use and other problem behaviors. Heaven and his colleagues (2007) studied the scholastic outcomes of various crowd memberships and 
report poorest academic achievement among members of the "rebel" crowds. As the number of studies concerning the impact of adolescent crowds increases, approaches to studying this social phenomenon deserve researchers' scrutiny. In order to make claims regarding the effect of crowd membership on adolescent functioning, research on adolescent crowds must be based on an accurate identification of crowd members and crowd attributes, yet there is an inadequate understanding of just exactly what a crowd $i s$. The lack of consensus on the attributes of crowd members (e.g., Brown, Lohr, \& Trujillo, 1990; Urberg, Değirmencioğlu, Tolson, \& HallidayScher, 2000) is an indication that crowds are not easily identifiable groups to which students belong. As stated by Sussman et al. (2007), "Comparison of assessment techniques is needed for a better understanding of the parameters of group identification" (p. 1624). Current adolescent crowd research generally takes one of four approaches to determining crowd membership of its sample: 1) Peer-ratings of subjects' crowd membership; 2) self-identification; 3) grouping by behaviors or characteristics; or 4) qualitative approaches such as ethnography or content analysis. This article critically evaluates these research approaches, pointing out the limitations that threaten the validity of their results. To begin, the varying definitions of adolescent crowd will be reviewed.

\section{What Is an Adolescent Crowd?}

Brown, Mory, and Kinney (1994) claim that, "crowds refer to collections of adolescents identified by the interests, attitudes, abilities, and/or personal characteristics they have in common"(p. 123). Different from cliques, which are interaction-based peer groups adolescents who "hang around" together - Brown (1990) defines crowds as "reputation-based collectives of similarly stereotyped individuals who may or may not spend much time together" (p. 177). Brown describes cliques as "behavioral phenomena," contrasted with crowds, which are 
"more cognitive phenomena, in which assignments are determined by judgments about someone's personal characteristics" (p. 188). Dunphy (1969) describes crowds as collections of cliques whose members gather for major social activities such as weekend parties. Urberg (1992) claims that some crowds may be reputation based, while others are interaction based: "Jocks and burnouts are more likely to be interaction based than such crowds as loners and nerds" (p. 440). In a recent review of the literature, Sussman, et al. (2007) use the term peer group identification rather than crowd, "because peer group types may be self- or other defined, and may pertain to a larger collective or to actual peer group interactions" (p. 1603). Among the studies reviewed here, there are various definitions (see Table 1). In some studies, no definition of the crowd is found or the definition is not clearly stated. In these cases, when possible, statements that suggest the researchers' conceptualization of crowds are included in Table 1.

In the US, with its compulsory secondary education, adolescent crowds are a schoolbased social phenomenon. They are not found in every school (Urberg, Değirmencioğlu, Tolson, \& Halliday-Scher, 1995) - although a school without this social phenomenon is the exception nor do they have the same names where they are found (Sussman, et al., 2007). The reasons for differences in the appearance or absence of crowds have not been examined.

Brown, Mory, and Kinney (1994) suggest that "crowds have two major functions: They foster individuals' development of identity or self-concept, and they structure social interactions" (p. 124). Although Erikson (1968) believed that adolescents experiment with different identities, crowd membership may not be a mutable characteristic like style of dress or sociability. Varenne (1982) found that adolescents could easily adopt the "diacritic marks" of a crowd, yet not become recognized as part of that crowd. Some research has found characteristics and behaviors poor predictors of crowd membership (Stone \& Brown, 1998), although others have used these 
to make crowd assignments (e.g., Strouse, 1999; Youniss, McLellan, \& Mazer, 2001). If crowds do, indeed, foster adolescents' identity, it seems they would have greater control over their crowd affiliation. Brown (1990) states "in a sense, adolescents do not select a crowd to join so much as they are thrust into one by virtue of their personality, background, interests, and reputation among peers" (p. 183). These aspects of the individual, however, have not been the subject of much research on adolescent crowd affiliations. Instead, such factors as appearance (Buff, 1970; Stone \& Brown, 1998), family SES (Hollingshead, 1975), attitudes (Cohen, 1979; Rigsby \& McDill, 1975; Strouse, 1999), and academic behaviors (Stone \& Brown, 1998) have received greater attention. Some researchers have defined crowds as interaction based, with the assumption that crowd membership can be identified by asking what crowd an adolescent "hangs out" with (Brown, 1990; Heaven et al., 2005; Sussman, Dent \& McCullar, 2000).

These various definitions of the crowd each indicate a different methodology. If crowds are defined as interaction based, they can be identified by the relevant interactions among adolescents. If crowds are based on an individual's behavior, this too can be identified. Reputation, on the other hand, is not a clear concept that can be readily operationalized. There is a disconnect in the research between crowd affiliation (a choice made by the adolescent) and crowd placement (an assignment made by an adolescent's peers). This disconnect presents major problems to the study of adolescents in their social environment. That is, different phenomena may be under investigation when researchers employ different self- and peer-identification crowdmethods. A great deal of research has been conducted without addressing these important differences, leading to results that may not be replicable or comparable. The objective of this article is to identify the problems with research on adolescent crowds conducted with differing 
methodologies that have developed and discuss their implications for our conceptual understanding of adolescent crowds.

\section{Research on Adolescent Crowds}

\section{Sampling}

One advantage of quantitative research is the ability to generalize findings from a sample to a larger population. With clear definitions of theoretical constructs and control of the potential errors in a study, one can have confidence that the findings will apply on a larger scale. In order to generalize findings, the sample studied must be representative of the population (Gall, Gall \& Borg, 2003). Adolescent crowds present a unique problem in sampling. If, instead of crowds, researchers investigated racial groups in a school, a researcher would include each racial group and select a sample that approximates the racial makeup of the school. Similarly, in the case of adolescent crowd research, the samples to be studied must represent the crowds that exist in the school. Each crowd should be identifiable by its boundaries. Who is in the crowd and who is outside of it? This is not such an easy task, particularly complicated by the multiple definitions of crowds.

To describe the dilemma faced by crowd researchers, we can use hypothesis-testing logic as an analogy. In order to create a representative sample of a single crowd, the researcher must accept into the sample those subjects who are in the crowd and reject those who are not in the crowd. If a subject is not in a crowd, but the researcher identifies her as being in the crowd, the result is analogous to a Type I error - the null hypothesis (subject is not in the crowd) was rejected incorrectly. A subject who does not belong in the sample is included inappropriately. If a subject is actually in the crowd being studied, but the researcher does not identify him as a 
crowd member, the result is like a Type II error - the null hypothesis (subject is not in the crowd) was accepted incorrectly. A subject who belonged in the sample is not appropriately identified.

The possibilities for both Type I- and Type II-like errors in our sampling example are greatest when the boundaries of the crowd are not sufficiently delineated. Without an accepted definition of the adolescent crowd, describing such boundaries is extremely difficult. This important assumption is consistently violated in approaches to the study of adolescent crowds. Without a decision about who is to be studied (i.e., how to define the crowd), such errors in classification will continue to threaten the validity of research results. The following review of research methodologies used in adolescent crowd research highlights the challenges inherent in each.

\section{Research Methodologies}

Social-Type Rating. As part of Hollingshead's (1975) ethnographic study, he selected representatives from each grade and social class and asked them "to evaluate the members of their school class and all other students they believed they knew well in terms of their reputation in the student group" (p. 164). Schwendinger and Schwendinger $(1985 ; 1997)$ refined this method of assigning crowds in their study of delinquency. They did not use the term crowd, preferring to name adolescent crowds by the metaphor they see as representing behavior (e.g., jocks, surfers, nerds). "We call these labels 'social-type metaphors' because their meanings, among other things, signify social regularities in personal behavior" (1997, p. 72). Schwendinger and Schwendinger's social-type rating method utilized "social-type raters" who were chosen from the top decile of subjects listed most frequently as "regular friends" to other subjects "higher peer status" students. Each rater and a friend they invited along were shown pictures of every student in their grade and gender category and asked to "use one or more of the metaphors 
in each response to four questions: 'What type does the youth look like?' (Alternatively, 'Is his or her dress and hairstyle identified with a type of youth?') 'What does the youth act like?' 'What kinds of youth does he or she associate with? And finally: 'What kind of youth is he or she generally identified as?"” (p. 75). Students could be identified as "multiple-type." A "socialtype profile" was created for each person, representing the proportion of ratings each person received on each social-type dimension, allowing for what the authors suggest is likely the Rashomon effect, the differing "truths" from each rater's perspective (Roth \& Mehta, 2002).

This approach to identifying crowd affiliation addresses the problem of a lack of consensus on crowd placement among peers: a student's social-type profile was developed from a proportion of ratings, taking into consideration the multiple crowd placements that some students were likely to be assigned. Schwendinger and Schwendinger's (1985) method has been modified and abbreviated in many other studies. Based on their methodology, Brown (1989) created a "Social Type Ratings Interview Manual" that describes his procedures in detail. Rather than beginning with friend lists, school administrators are asked for a list of names of students in each grade who "represent a good cross-section of the student body" and who are likely to enjoy participating in interviews concerning the school's social structure. From this list, students are asked to participate in a focus group interview. The purpose of this group interview is to generate a list of crowd names used in the school, crowd types, and a list of leading members of each crowd. Clasen and Brown (1985) reduced the number of crowds named in the interview into 11 crowd types based on the crowd behavioral characteristics found in Brown, Lohr and Trujillo (1990), then used these crowd types to make assignments of rated students.

Leading members are contacted to act as the social-type raters and are asked to include a friend. Brown's (1989) method requires at least 10 ratings for every student in the school, 
meaning that other students must be found to act as raters. Rather than using photo ids of the students to be rated, Brown uses a student roster. Student social-type raters are asked "Which crowd, among the ones listed here [from the focus group interviews] MOST students in your class would say THIS person is part of?” (p. 20).

Brown's (1989) modified social-type rating (STR) method has been used in numerous studies (Brown, Eicher, \& Petrie, 1986; Brown \& Lohr, 1987; Brown, Mory \& Kinney, 1994; Brown, Mounts, Lamborn, \& Steinberg, 1993; Clasen \& Brown, 1985; Dolcini \& Adler, 1994; Stone \& Brown, 1999). Brown and Lohr (1987) eliminated the time-consuming aspects of peer rating sessions by asking students to name major crowds in their school, give stereotypic traits for each crowd, rank order their status, and name five classmates they consider to be members of the group. Dolcini and Adler used Brown's modified STR method in a study of adolescent risk behavior. Twenty-one $8^{\text {th }}$ graders participated in the focus group interview and $168^{\text {th }}$ graders acted as social-type raters. These 16 raters classified 183 of their $8^{\text {th }}$ grade peers, meeting the requirement of at least 10 raters for each student.

Using Brown's (1989) method, each student must be placed in one crowd, unlike the proportional social-type profile of Schwendinger and Schwendinger's (1997) method. Because there is frequent disagreement among raters, Dolcini and Adler's (1994) subjects were assigned to a crowd if at least half the raters put them in that crowd and less than one-third of the raters placed them in another crowd, also according to Brown's (1989) recommendation. The success of meeting even this requirement depends largely on the representativeness of the raters.

As Brown (1990) states, “individuals with equivalent person-perception or group perception skills may perceive the peer group system in quite different terms" (p. 181), describing the ambiguity of crowd boundaries. Brown and Mounts (1989, cited in Brown, 1990) 
report that, "whites were more likely than blacks to mention a black crowd and to assign a large proportion of students to this crowd" (p. 181). A broad, representative group of raters is necessary for accurate crowd assignment according to Brown's procedure. Brown points out that, "students from the loner and unpopular (nerd) crowds are not good STR candidates. Typically, they don't know enough classmates well enough to rate into crowds" (p. 15). Schwendinger and Schwendinger (1985) also chose raters from the top decile of students named as "regular friends," limiting their peer raters to the popular students. Without the viewpoint of the unpopular students, is the crowd assignment truly representative? It is possible that unpopular students are aware of other crowds within the school that the popular students are not. If only the popular students are given a voice in determining reputation, the likelihood of Type I- and II-like errors in identification of the sample increases.

Although the STR method is frequently used in crowd research, the assumption that crowd assignment is successful even when there is significant disagreement between raters is difficult to accept. Disagreements among raters are common, and the requirement that only half of crowd assignments be in agreement, with no more than one-third assignments to one other group, is a major problem in identifying the sample. High agreement between raters would increase confidence in the sample, but no measure of interrater reliability is reported in any of the studies reviewed here. Reliability of the STR method "remains untested" (Brown, 1999, p. 64). An interrater agreement of .5 would not be considered acceptable in most research utilizing independent raters. There is the distinct possibility that a second researcher in the same school would find different crowd assignments simply by using different raters, although this possibility has not been studied. Similar to traditional test-retest reliability procedures, it would be interesting to examine the consistency of ratings by individual students for their peers within a 
short time frame (e.g., 1 month). Of course, this research would be compromised by instability in crowd membership (Kinney, 1993, 1999; Strouse, 1999), yet it would provide some evidence of rater reliability.

Some researchers simply place hard-to-classify students into a "floater" crowd (Dolcini \& Adler, 1994). In a return to Schwendinger and Schwendinger's $(1985 ; 1997)$ technique, Brown, Mounts, Lamborn and Steinberg (1993) suggest a "series of proportion scores representing the percentage of raters... who placed the student in a given crowd" (p. 471) rather than making categorical assignments based on the majority of rater placements. Although it does present difficulties in statistical analyses, this proportional score is a positive step in the direction of recognizing the complexity of crowd membership. The STR approach to crowd research is a methodology designed to identify students according to their reputation among peers. However, reputation may mean different things to different raters, leading to a possibility that the crowds identified do not reflect accurate assessments of crowd membership. It also does not take into account the individual's beliefs about their crowd affiliation.

Self-identification. The most frequently used method for determining crowd affiliation is some form of self-identification. Self-identification does not acknowledge the reputational basis of crowd placement. Can an individual know with accuracy her or his reputation among peers? Brown (1990) states, "crowd affiliation indicates who an adolescent is - at least in the eyes of peers" (p. 184). There may be topics that should be studied from this perspective, for example, how behavioral change can affect one's reputation among peers, or the effect of peer's stereotyping by reputational crowd. In many cases, however, what researchers need to understand is the adolescent's perception of his or her crowd affiliation. For certain research questions, how adolescents recognize their place in the social structure of the school may be 
more important than their reputation among peers. How this relates to their reputation among peers may be important, but the research question should determine which is of greater interest. Common self-identification methods, however, are not consistent in their request to participants, sometimes asking what crowd the subject identifies with and sometimes what crowd others may consider them to be a part of. These various approaches to self-identification may result in widely disparate responses.

The way in which self-identification is pursued varies greatly. Mosbach and Leventhal (1988), in their study of smoking behavior, asked $3537^{\text {th }}$ and $8^{\text {th }}$ graders in a structured interview, "We would like to know what sorts of groups or types of people there are in this school. I mean groups like freaks and jocks. Can you tell me what the different groups are?" (p. 239). They then asked the students "With which group do you most enjoy doing things?" (p. 239). The problem with this approach is that it is likely to identify one's clique rather than crowd. Urberg, Değirmencioğlu, Tolson, and Halliday-Scher (1995) compared friendship nominations and crowd membership and found that friends are frequently not in the same social crowd. Less than $50 \%$ of best friends were in the same crowd (as identified with their STR method). La Greca, Prinstein and Fetter (2001) and McFarland and Pals (2005) had similar findings. Sussman, Dent and McCullar (2000) make the same assumption in asking for selfidentification of interaction-based groups: "People often hang out in different groups at school. Circle the letter of the one group that you feel that you're most a part of' (p. 193). Heaven and colleagues (2005) do the same: "Indicate the ‘kind of students you hang around with' by selecting one group from a list of group descriptions" (p. 315). These requests also do not give respondents an option to select multiple group memberships. When given the opportunity to selfidentify, adolescents often choose multiple groups. Out of 905 adolescents in Youniss, McLellan, 
and Strouse's (1994) study, 209 reported identification with two groups and 93 reported three or more. Not allowing self-identification with multiple crowds increases the likelihood of Type Ilike errors - students who would have reported being in a crowd are not able to report this crowd membership. Moreover, there is no data to indicate that students in multiple crowds feel more strongly affiliated with one particular crowd over another, compounding the problems associated with methodologies that require students to choose one crowd.

Another common request for self-identification asks respondents to select the crowd with which they most identify (Johnson, 1987; La Greca \& Harrison, 2005; La Greca, Prinstein \& Fetter, 2001). Eccles and colleagues (Eccles \& Barber, 1999; Barber, Eccles, \& Stone, 2001) asked students which of the characters in the movie The Breakfast Club - the Princess, the Jock, the Brain, the Basket Case, or the Criminal - was most like them. Although this does not confound friendship networks with social crowd, identifying with a crowd does not necessarily indicate one's reputation. It is unclear whether adolescents know their reputation or how much that is a part of their identity. As Varenne (1982) points out, they may adopt all the "diacritic marks" of the crowd, yet not be considered a member. If the assumption is that self-identification is more important than one's reputation, this method is appropriate. A problem with The Breakfast Club approach is that so few crowd types are possible to choose from. Subjects were offered only these five possible groups to identify with, even though many studies have found the largest crowd in a school to be normals or average students (Heaven et al., 2005; Mosbach \& Leventhal, 1988; Stone \& Brown, 1998; Sussman, Dent, \& McCullar, 2000; Urberg, 1992; Urberg, et al., 2000). Students who believe they are normals were not given an option for selfidentification. Such subjects would have been assigned into a crowd to which they might not have been associated- as in a Type-II error. 
Several researchers attempt to access subjects' reputation by asking them to report what crowd others would put them in (McFarland \& Pals, 2005; Urberg, 1992; Urberg et al., 2000), yet there has only been one study to examine consistencies between self-report of peer crowd placement and peer ratings. Urberg, Değirmencioğlu, Tolson, and Halliday-Scher (2000) attempted to do this, using social-type rating and self-identification (asking them to name "the social crowd most of your classmates would say you belong to now" [p. 432]). This study was unfortunately plagued with methodological problems, beginning with the inability to utilize social raters within the school. They were not given permission to do peer ratings because "the superintendent of the system would not allow us to ask adolescents to assign crowd names to their peers" (p. 431). They were able to find 60 students from the school "in a variety of settings" to complete the ratings. These 60 raters had very poor consensus in naming students to social crowds, requiring the researchers to relax the standard of agreement in crowd assignments. Urberg et al. report a fairly high consensus between self- and peer-ratings with a contingency coefficient of .66 , but this summary statistic masks a number of large variations appearing in the table comparing the two. For example, 121 people reported that others would consider them to be Preps, but only 70 of them are peer-nominated as Preps. Only 1 student (out of 22) who reported that others would consider him or her to be a Brain was named a Brain in the peer rating. The rest of the self-identified Brains were named Nerds by their peers, except 1 named Average. The methodological problems with this study make it difficult to say with conviction that adolescents can reliably report their reputation.

In addition to asking students to name peers belonging to the crowds in their school, Brown and Lohr (1987) asked subjects to "indicate the group to which they felt most of their classmates would say they belonged" (p. 50), again framing self-identification not as interaction 
based or identification with a crowd, but attempting to access subjects' knowledge of their reputation among peers. Although Brown and Lohr matched these subjects' crowd placement by peers with their "reflected appraisal of group affiliation" (p. 50), they did not report on the accuracy of students' reflected appraisals.

In yet another way of approaching self-identification, Durbin, Darling, Steinberg, and Brown (1993) and McFarland and Pals (2005) asked subjects multiple questions. Durbin et al. asked adolescents to report

a) the crowd to which most of their classmates would say they belonged;

b) the crowd to which most of their classmates would say most of their friends belonged; and

c) the crowd to which they would like to belong if they could. (p. 92)

McFarland and Pals asked subjects to report

1) Ideal: "If you could belong to any crowd, which one would you most want to be part of?" (if none, write "none")

(2) Actual: "Which crowd would you personally say that you belong to?" (If you don't think you belong to any of the crowds on the list, write "none")

(3) Public: "Write the name of the one crowd that your classmates would say you belong to." (p. 294)

Rather than creating an index from the three questions, Durbin et al. reported their findings by each question individually (e.g., statistical differences on parenting style by crowd are reported by each question: "Chi squares for the boys were as follows: desired crowd, $\chi^{2}(3, N=256)=$ 12.8; friends' crowd, $\chi^{2}(3, N=361)=10.6$; and reputational crowd, $\chi^{2}(3, N=331)=9.4 "$, p. 96). This method of reporting makes interpretation of findings difficult for establishing correlations 
between the different types of self-reports. McFarland and Pals were mainly interested in identity change within individuals over time and thus did not analyze their data to examine consistencies across the three self-report questions.

Self-identification is the simplest method of collecting crowd affiliation, but the studies cited here have asked subjects to respond to different questions - who they "hang out with," who they identify with, who they want to be identified with, who others think they are, or a

combination of all of these. There is no research to indicate how responses to each of these selfidentification questions differ. The construct of crowd membership remains undefined. If the definition of crowd as reputation based is accepted, no credible evidence exists that individuals can report what crowd others would place them in, nor do we know that this response is consistent with their beliefs about their crowd membership. When asked with which crowd they most identify, do adolescents respond with the crowd in which others would consider them a member, or the crowd to which they would most like to belong? Durbin et al. (1993) claimed that adolescents tend to overreport membership in high-status crowds when self-identifying, but do not cite evidence for this claim. In Stone and Brown's (1998) study, they report that older students were more likely to "identify with" high status crowds than younger. Stone and Brown, however, determine "self-identification" of crowd membership from subjects' reports of their own actual behaviors and characteristics rather than their desired or presumed affiliation with a high-status crowd. Identification using this approach is not necessarily a conscious process, nor does it get at subjects' perceptions of crowd affiliation. In addition to the noted lack of agreement between peer raters using the STR method, self- and peer-identification are also likely to be different for many adolescents, particularly when the questions designed to elicit self- 
identification vary so greatly. Researchers must be aware of the approach that is most relevant to their research question.

Grouping by behaviors/characteristics. Crowds are often believed to share "interests, attitudes, abilities, and/or personal characteristics" (Brown, Mory \& Kinney, 1994, p. 123) or to "vary substantially in normative attitudes, interests, and behaviors" (Clasen \& Brown, 1985, p. 453). These differing behaviors and characteristics are commonly considered part of the definition of a crowd. Coleman (1961) collected voluminous survey data on nearly 9,000 students in 10 high schools. His surveys for boys, girls, and parents asked about dating, academic, athletic and family activities. Many years later, Cohen (1979) used factor analysis with Coleman's data to find “adolescent subcultures" based on subjects' responses. Friesen (1968) conducted a similarly large $\left(\mathrm{N}=10,01910^{\text {th }}\right.$ to $12^{\text {th }}$ graders $)$ survey of characteristics adolescents believe to be significant to becoming part of the "leading crowd" of Coleman's research. England and Petro (1998) asked $887^{\text {th }}$ graders to label the different "types" of students in their school and then to list "things which make the students in that group different from students in other groups. For example, you might describe the things typical members of the group do, the way theylook, the kinds of clothes they wear that are different from other students, how they get along with others, how they feel about school work, what classes they like, or how smart they are" (p. 354-355). In a different sample of $877^{\text {th }}$ graders, they asked participants to choose which of the previously listed 44 characteristics applied to each named crowd. Analysis of these descriptions found differences between crowds on such characteristics as academic interest, dress style, and sociability.

Strouse (1999) used cluster analysis with the National Education Longitudinal Study of 1988 (NELS:88) data for 7,999 $10^{\text {th }}$ and $12^{\text {th }}$ graders to group by behaviors. She found five 
groups: All-Around (popular, good student; $42 \%$ of $10^{\text {th }}$ grade females, $46 \% 10^{\text {th }}$ grade males), Studious (academically inclined; $9 \%$ of $10^{\text {th }}$ grade females, $17 \% 10^{\text {th }}$ grade males), Average (moderate ratings on most items; $24 \%$ of $10^{\text {th }}$ grade females, $17 \% 10^{\text {th }}$ grade males), Disengaged (withdrawn, socially inactive; $16 \%$ of $10^{\text {th }}$ grade females, $12 \% 10^{\text {th }}$ grade males), and Deviant (partying, very social, troublemaker, not concerned about finishing high school; $9 \%$ of $10^{\text {th }}$ grade females, $8 \% 10^{\text {th }}$ grade males). Strouse defined crowds based on the subjects' similar behaviors and attitudes. It is unclear how her sample would differ from crowds identified using either the STR method or self-identification.

Brown, Lohr and Trujillo (1990) asked 93 college students and $3107^{\text {th }}$ to $12^{\text {th }}$ graders to list descriptors of 8 crowds. They found similar characteristics differentiating crowds by dress, sociability, academic orientation, extracurricular participation, weekend activities, and school hangout. Consensus between college students and teenagers was not $100 \%$ on all crowds or characteristics, but was highest on sociability and lowest on academic attitudes. Stone and Brown (1998) describe the teenage sample results of the Brown, et al. study and extended on it in their Study 2. Using a brief STR methodology, 255 adolescents were assigned by peers to one of 7 crowds. These participants were asked to choose the characteristics that best described each crowd (e.g., in the domain of dress, choices were "casual, neat," "expensive/stylish," "tough," "messy, dirty," "out-of-style," or "really varies"). Seventy-eight percent of pairings in loglinear analysis differed in all five domains, indicating that crowds could be differentiated statistically by these characteristics. At least one domain for each crowd (except the Black crowd) had $60 \%$ consensus among respondents, but the percentage of respondents selecting specific behaviors for a crowd varied widely. Crowd membership appears to affect perceptions of other crowd descriptors. There were significant differences in the pattern of descriptions of each crowd based 
on the peer-rated crowd membership of the respondents. In other words, the perceived crowd characteristics differed among the raters. Behaviors and characteristics are not sufficient to identify crowd affiliation, as Varenne (1982) noted. If the research question is related to adolescent behaviors or characteristics, grouping subjects in this way may be the most appropriate method, but research indicates that this is not how crowd placement is determined (Brown, Lohr, \& Trujillo, 1990; Stone \& Brown, 1998). No studies reviewed here explored the possibility that behaviors and characteristics are related to crowd affiliation.

In addition to the assumption that crowds shared characteristics, researchers sometimes assume that adolescent social crowds are made up of friends. Dunphy's (1969) definition of crowds proposed that they are composed of multiple cliques. The actual friendship among crowd members is not so neatly delineated. La Greca, Prinstein and Fetter (2001) asked students to identify their three best friends and give their friends' crowd affiliation. Although $82 \%$ of participants reported at least one best friend in their same crowd, many reported their friends were in a different crowd. Urberg (1992) found similarly low percentages. McFarland and Pals (2005) reported, "adolescents from the three largest crowds had about 50\% of their friendships from their own crowd"(p. 440),

Schwendinger and Schwendinger (1997), in a re-analysis of their 1963 to 1967 data, found correlation coefficients of around .70 between social-type profile and friendship nominations for all students by grade and gender. One possible reason for this higher correlation is their use of a social-type profile rather than a specific crowd assignment. When subjects are identified as partially belonging to multiple crowds, there is a greater likelihood that a friend will be in one of them. 
Ethnographic studies. Early studies of crowds emerged from ethnographic research, an approach favored by cultural anthropologists. Ethnographers collect data from observations of adolescents in their school settings, and from conversations or interviews. Hollingshead (1975) studied adolescents in the Midwestern town of Elmtown in the early 1940's. Buff (1970), Eckert (1989), Larkin (1979), Varenne (1982), and Kinney (1990) all report on adolescent lifestyles from the perspective of an observer, with interview data providing support for their interpretations. Due to the extensive nature of such observations, researchers must focus on only a subset of the student population. Kinney, for example, elected not to study the grits, a large segment of the population at the high school he studied. Eder (1985) chose to limit her ethnographic study to the girls in a middle school cafeteria and Merten (1996a) observed and interviewed 4 boys who had been rejected by their peers. Findings from this research that describe a limited sample are not intended to be generalized to all adolescents.

Despite this acknowledged methodological limitation, summaries of the research on adolescents often contain references to ethnographic studies as if they apply to the more general population. For example, Corsaro and Eder (1990) cite Eder's ethnographic study of the girls in a middle school cafeteria with this statement: "In early adolescence, middle-class females gain status through activities such as cheerleading and through friendships with popular girls (Eder 1985)" (p. 210). In this example, Corsaro and Eder inaccurately imply that Eder's findings from the limited sample may be applied to all middle-class female adolescents. Researchers using these methods need to be careful not to overgeneralize their results to other populations Another limitation of ethnographic research arises from the difficulty of building credibility with the population to be studied. This is likely to be particularly difficult in the case of adults establishing credibility with adolescents. Once he was sufficiently accepted by the 
adolescents he chose to study to begin data collection, Kinney (1990) became associated with them and was not accepted by the adolescents who rejected his informants. Although much can be gained from an association with select students, ethnographic researchers must base their interpretations on a partial view of the adolescent social environment.

Researchers engaged in ethnographic study look for clues to the social structure in their observations or in the language of the participants. As in the STR method, crowd labels come from the students themselves. It is not difficult to learn about the crowd labels in a given school, especially if a suitable informant is found (Kinney, 1990). In reminiscing about how crowds began to form after elementary school, one student says, "We were all the same. We weren't all Jocks but there's no such thing as Burnouts until junior high. So we were all just friends" (Eckert, 1989, p. 82). Buff (1970) reports, “One greaser male told me, 'The greasers hang out in the stores and commercial places...The dupers hang in the school or schoolyards" (p. 75). Varenne (1982), who uses the term "cliques" for the groups others call crowds, describes the ease of identifying crowds in his ethnographic study:

It did not take us more than a few days to "discover" that there were indeed cliques in Sheffield, to identify the main members of the various cliques, and to adopt, in our field notes, the labels which then seemed totally appropriate. We talked of the "jocks" and the "freaks" with great ease. (p. 217)

Although not generalizable, repeated findings of similar crowd types and social structures in ethnographic studies suggest the possibility that these exist in other secondary schools. Garner, Bootcheck, Lorr, \& Rauch (2006) conducted a large-scale study, collecting both qualitative and quantitative data, that provided insight into the ways in which schools vary. In this study of seven schools, they found differing climates that were reflected in the crowds and 
status markers. For example, in some schools, status came from athletic success, whereas in others attractiveness and wealth were most important. The location of the school, ethnic composition, economic situation of the students, and the adult involvement affected the social makeup of the school (e.g., the "fragmentation" into many diverse crowds at one school, large oppositional crowds in another). Similar types of crowds may appear across different studies (Sussman et al., 2007), but researchers should consider the larger school context to better understand the nature and function of adolescent crowds. Although large in scale, the various methodologies used in the Garner et al. study were not adequately reported. Replication of the study would be impossible from the description provided, which limits the ability to assess the study's validity. In general, qualitative researchers must describe in greater detail than quantitative researchers their sample, methods and level of interaction with their participants to enable other researchers to evaluate their result findings (Hartmann \& Pelzel, 2005).

Content analysis. A basic type of qualitative research used frequently in learning about adolescent crowds is the in-depth analysis of interview data or responses to open-ended survey questions. Through content analysis, definitions and descriptions emerge from the data (Giorgi, 1970; Husserl, 1962). Voluminoús interview data and open-ended survey responses require hands-on (eyes-on) analysis, with personal attention to telling details in the language. The researcher must have the ability and impartiality to perceive significant messages in the data and some form of yalidity check is necessary (e.g., member checking, peer review).

Downs and Rose (1991) learned about the crowds in their sample of adolescents in a hospital-based drug and alcohol crisis intervention program from responses to interview questions. Once they determined crowd affiliation from the informants' responses, statistical analyses were conducted on other measures. This qualitative analysis resulted in crowds similar 
to those found in nearly all previous studies - brains, jocks, normals, and druggies. Two independent coders determined the crowd affiliation from the content analysis, with an interrater agreement of $93 \%$.

In their study of 905 high school students, Youniss, McLellan and Strouse (1994) analyzed responses to a survey originally conducted by Kahn (1989). A list of crowds was generated from the existing crowd literature. Students checked the crowd (or crowds) to which they belonged and gave descriptions of those crowds. From these descriptions, characteristics of each crowd were developed. The authors expressed surprise at the number of students reporting membership in multiple crowds and at the tendency for characteristics to be shared by multiple crowds. One might assume that if crowds share certain characteristics, the likelihood that students may belong to multiple crowds would increase. Given that methods in crowd research tend to limit self- and peer reports to one crowd, there is limited information about shared characteristics and its impact on crowd membership in the existing literature. By imposing the crowd names from existing research on the informants in the first phase of this study, rather than learning from the students what crowds existed in their schools, however, Youniss et al. may have limited the responses of their informants.

Brady (2004) performed content analysis of interview data, providing numerous subject comments that support his findings regarding the many crowds his $26811^{\text {th }}$ grade informants describe (jocks, teckers, preps or preppies, nerds or geeks, Goths, stoners, rappers, skaters, and punks) along with each group's position in the status hierarchy. Unfortunately, his interview procedures are not well described, making his precise methodology and findings inconclusive. Accurate reporting of methodology is critical to assessing the validity and rigor of any research, 
but particularly qualitative research, which relies heavily on the investigator's interpretations of data (Hartmann \& Pelzel, 2005).

Qualitative research such as ethnography and content analysis can provide context to the study of crowds and can be particularly useful in helping to develop theory concerning the purpose and function of crowds (Hartmann \& Pelzel, 2005). The assumptions of qualitative research differ from the quantitative approaches described here (i.e., STR, self-identification, grouping by behaviors) as the debate between Brown (1996) and Merten (1996a, 1996b) reveals, indicating that the problems identified in the quantitative approaches are not necessarily mirrored in qualitative. Yet the nature of qualitative methods makes obtaining the complete picture of adolescent crowds within a given school impossible. Moreover, qualitative methods suffer from the same problem as quantitative methods: It is the researcher who decides on the definition of a crowd and determines the criteria for inclusion into crowds. As such, a combination of methodologies may be necessary to determine the context of crowds and crowd types within a given school to establish ecological validity (i.e., qualitative) and standard methods to determine crowd placement and/or crowd affiliation (i.e., quantitative). In doing so, we will be able to more accurately address the function of crowds for adolescent development and investigate how crowd membership may predict important developmental outcomes.

Finding Boundaries

An important assumption of the questions that frame the various research approaches described above (e.g., "What is the definition of a crowd?" "Who is in the crowd?") is that adolescent crowds are a group. Merten (1996b) points out that crowds do not fit the description of a group, which has "identifiable boundaries and membership" (p. 40). Rather, crowds are better understood as cultural categories that do not meet the more rigid definition of a group. 
Cognitive representations of a category are associated with a prototype, an exemplar with all the "features assumed to be true of the group as a whole (the group stereotype)" (Messick \& Mackie, 1989). Membership in a category is thus an imprecise determination, one that will vary based on the social learning and experiences upon which an individual's cognitive representation is founded. Perhaps there would be agreement among social raters on the prototype member of each crowd, but the members who exist farther from the central prototype in the radial category will be harder to classify (Rosch \& Lloyd, 1978). Each social rater will bring his or her impression of a prototypical crowd member to a rating session. Moreover, one wonders whether crowd membership may be more stable for prototype members of particular crowds compared to those crowd members more loosely associated with a crowd or multiple crowds. Although we know that crowd membership appears less salient in the lives of older adolescents compared to younger adolescents (Brown, et al., 1986; Coleman, 1974), no studies were found that examined the stability of crowd membership in the short-term.

Recent research (Cross, 2008; Delsing et al., 2007) indicates that many adolescents identify with multiple crowds, with particular patterns evident in the various crowd associations. Statistical methods such as factor and cluster analysis make it possible to explore the categorical nature of crowds. Crowd categories are likely to vary according to the definition applied. For example, a sociometric approach (e.g., Brown, 1989; Brown et al., 1986; Brown \& Lohr, 1987; Schwendinger \& Schwendinger, 1985, 1997) may find different categories of membership than would be found using an interaction-based approach (e.g., Eckert, 1989; Heaven et al., 2008; Sussman, et al., 2000). In regard to developmental research, interaction-based approaches may be identifying friendships and cliques that may or may not overlap with crowd membership for an individual as measured with the sociometric approach. This is an important theoretical issue 
given that different developmental functions have been associated with crowds compared to friendships (identity vs. intimacy, respectively; Vérroneau \& Vitaro, 2007). This issue must be more closely examined in order to elaborate theoretical models for developmental outcomes associated with the adolescent peer environment.

The STR procedure could be enhanced by creating a more sophisticated stereotype of each group, with distinct delineations of the features of the prototypical crowd member. Brown, Lohr, and Trujillo (1990) attempted to do this, but found that consensus was extremely difficult among their college student sample $(n=93)$ and their teen sample $(n=310)$. They considered consensus on a crowd's description to be when $65 \%$ of respondents described them the same way. "Of the 42 distributions assessed in the college sample (six categories [e.g., dress, sociability, academic attitudes, etc.] for each of seven crowd types, excluding the 'miscellaneous' groups), 60\% showed consensus. In the teenage sample, there was consensus on only $44 \%$ of the distributions analyzed" (p. 34). The varied cognitive representations of crowds make consistent placement of peers an extremely difficult task.

Undefinable group boundaries hinder the ability of research methods to answer questions related to crowds. Without a conceptual framework of the adolescent social environment that includes a comprehensive definition of crowd, researchers may be looking at different phenomena, rather than studying a single phenomenon. This possibility has not been acknowledged in the crowd research, leading to potentially inconclusive results. The primary problems with the various methods for studying adolescent crowds stem, in part, from the multiple definitions available,. This issue has not been addressed in the literature and yet, hinders the efforts of researchers in their development of theoretical models to explain the function and developmental outcomes associated with adolescent crowd membership. 


\section{Moving Beyond Representation Toward Understanding}

Adolescent crowd research has been expanding on an unstable foundation. Knowledge has been gathered from varying perspectives, but not drawn together into a cohesive whole. Sussman et al.'s (2007) review of the literature describes the findings of 44 studies conducted without a clear description of adolescent crowds. In fact, Sussman, et al. combined the results of crowd studies that used each of the previously discussed methods to determine characteristics of five general crowd categories (Elites, Athletes, Deviants, Academics, and Others). The assignment of crowd names found in the reviewed research to these five categories was moderately reliable $(85 \%)$. These five crowds were then described on the basis of characteristics reported in the previous studies. The authors acknowledge the limitations of the "peer group identification" literature, but not the dramatic impact of these limitations. How much confidence should be placed in the findings of differences among crowd member behavior when the samples were identified with widely differing methods?

Perhaps most surprising, the authors state that "Knowing which adolescent peer groups are most likely to engage in problem-prone behavior can help better target preventive efforts" (Sussman, et al., 2007, p. 1623). We believe that statements such as these are extremely premature given the methodological problems within the area of crowd research. Much more evidence is needed to link accurate crowd membership with individual behavior before the idea of using crowd affiliation to target intervention efforts can even be considered.

How can such a major issue as identification of the sample be resolved? Differing definitions of crowd are not necessarily wrong, but they indicate a lack of understanding of the adolescent crowd phenomenon. What will be the impact of a failure to acknowledge the differences inherent in the various approaches to determining crowd membership? If 
membership in a crowd is empirically "proven" to indicate problem behavior through methodologies suffering from Type I- and Type II-like errors in identification, many adolescents will be subjected to inappropriate interventions, while those in need of support go without.

In his analysis of the "archaeology of the human sciences," Michel Foucault (1966/1970) describes a progression of knowledge in the sciences from a $16^{\text {th }}$ century acceptance of magical explanations based on the similarity of objects to a late $18^{\text {th }}$ and early $19^{\text {th }}$ century understanding of the functions shared in organic structures. The phase of knowledge-seeking between these two major time periods Foucault described as the search for identity and difference. Discriminating between objects, seeking the true identity of a thing, lead to the mechanistic worldview that dominated the $17^{\text {th }}$ century. In the effort to know the world through its identities, taxonomies were the order of the day. The study of natural history in the $17^{\text {th }}$ century was represented in tables, an ordering of plants and animals that shared visible characteristics.

The adolescent crowd literature is replete with examples of similar taxonomies: listings of the names used in various crowd studies (Sussman et al., 2007); listings of the "social-type metaphors" (Schwendinger \& Schwendinger, 1985); and descriptions of the behaviors of crowds (e.g., Brown, Lohr \& Trujillo, 1990; Cohen, 1979; Coleman, 1961; England \& Petro, 1998; Friesen, 1968). The initial phase of the STR method (Brown, 1989; Schwendinger \& Schwendinger, 1985) is a way of helping researchers create a taxonomy of crowd names in the school(s) being studied. With all of these representations, however, it is evident that crowds cannot be identified from lists. Many of the sampling errors described above result from an incomplete understanding of adolescent crowds. The reliability of our current study of crowds is in question in part because we do not understand the function of these social categories. In our efforts to understand the social world of adolescents, we are still struggling with "the primacy of 
representation." The emphasis on naming crowds to the exclusion of an understanding of the function of crowds suggests that crowd researchers need to make the move to a new episteme.

Adolescent culture is a relatively new feature of society, affecting most U.S. teenagers only since the 1930's (Steinberg, 2005). Research on adolescent culture began with the search for identities - who the adolescents and their peer groups are - and differences - how adolescent culture differed from adult culture. Efforts to describe the adolescent social environment dominate contemporary research: how adolescent culture differs from adult culture (e.g., Coleman, 1961); the characteristics of the culture (e.g., Brown, Lohr, \& Trujillo, 1990; Eckert, 1989; Gavin \& Furman, 1989; Larkin, 1979); how the described culture (crowd) relates to other behavior and outcomes (e.g., Dolcini \& Adler, 1994; Eccles \& Barber, 1999). Researchers are making efforts to develop an understanding of the function of crowds (Brady, 2004; Brown, Eicher \& Petrie, 1986; Brown \& Lohr, 1987; Clasen \& Brown, 1985; Kinney, 1990; Stone \& Brown, 1999; Strouse, 1999; Youniss, McLellan, \& Strouse, 1994), but findings are complicated by multiple definitions of the crowd. Problems arise when researchers attempt to determine the effects or correlates of the various crowds before they have fully addressed the issue of multiple definitions.

The lack of consensus on crowd placement among peer raters should also be of concern to crowd researchers. What is the meaning of disagreements among peer raters? Is it systematic? Can research on the effects and correlates of crowds be reliably replicated when using STR, selfidentification, or grouping by behaviors or characteristics? Sussman, et al. (2007) indicate that peer ratings of crowds might "provide a check" (p. 1603) to determine if individuals actually belong to the crowd. Such a check will only be accurate if the definition of "crowd" is the same 
for both the peer- and self-identification. More research is needed to determine how these different approaches to determining crowd membership may be related.

In writing of the adolescent peer environment, Brown (1999) suggests, "The task, then, is to design suitable measures of each process within the appropriate level or type of peer relationship" (p. 81). This task is also necessary for the study of the crowd, a subset of the larger adolescent culture. As each of the studies reviewed here was designed, the investigators decided on a definition of the adolescent crowd they wished to study. In some cases, their chosen definition was clearly stated, in others it was not (see Table 1). As a methodology was selected, the adolescent crowd to be studied was determined. Although all of these studies were about "adolescent crowds," the methodologies that follow from these various definitions may actually produce different subsets of adolescent culture. It is appropriate for the research question to drive the selection of a definition of the sample. The literature currently does not acknowledge these various definitions, however, making it appear that the adolescent crowd research is about a single phenomenon, not about various aspects of the adolescent social scene or adolescent psychological development.

In order to advance developmental outcome research and theoretical models of adolescent peer relationships, we can begin to address the issue of multiple definitions through greater specificity in terminology. Current research suggests the following terms: "reputational crowd," based on peer placement; "behavioral crowd," based on behaviors, attitudes, and/or characteristics; "interactional crowd," based on who "hangs out" together; and "affiliation crowd," based on the crowd one identifies with. Once the selected definition is emphasized, the next step will be to determine the composition of these various crowds. Do they overlap? Are they stable, or do adolescents move in and out of these various types of crowd in a systematic 
manner? What are differences between the members of each of these crowds? Greater attention to the type of adolescent crowd of interest to each research question will lead to new avenues of research, resulting in a greater understanding of the adolescent culture.

Missing from the current body of research is an analysis of the temporal nature of adolescent crowds (D. Merten, personal communication, September, 2007). Does membership in crowds change over time? Some studies have indicated that they do (e.g., Kinney, 1990; Strouse, 1999), but longitudinal studies of adolescents' social behavior are uncommon (c.f., Brown, Freeman, Huang, \& Mounts, 1992 cited in Brown, 1999; Eder, 1985; Kinney, 1990). In Heaven et al. (2008), the variables of interest were followed for 3 years, but crowd affiliation was examined only in the first year. The few existing longitudinal studies follow the students for only 2 or 3 of the 6 or 7 years they spend in secondary education. Crowd affiliation or placement may depend on a level of social development, either of the crowd or of the individuals in the crowd. It is imperative to learn what changes are occurring over the full span of an adolescent's exposure to the social environment in schools. Such studies would elucidate the processes and elements affecting the development of social categories, particularly if investigators focus on the different definitions of adolescent crowd (i.e., reputation, interaction, behavior, etc.).

At present, we can assume that research on the effects of crowds will continue on the basis of past research. Investigators will continue to determine crowd membership using the STR, behaviors or characteristics, self-identification, content analysis, and ethnography. As we evaluate the research conducted with these traditional methods, the definition of adolescent crowd should be kept in mind. An emphasis on which crowd definition best fits each research question and clarification of the definition selected will aid our common quest to develop an understanding of the adolescent social world. The goal of a comprehensive theory through which 
researchers can explore the challenging social environment of adolescents must be paramount in this quest.

\section{Acknowledgements}

The authors would like to thank Don E. Merten for advice on early versions of the manuscript and the two anonymous reviewers who provided useful suggestions for improvement. 


\section{References}

Barber, B. L., Eccles, J. S., \& Stone, M. R. (2001). Whatever happened to the Jock, the Brain, and the Princess? Young adult pathways linked to adolescent activity involvement and social identity. Journal of Adolescent Research, 16(5), 429-455.

Brady, P. (2004). Jocks, teckers, and nerds: The role of the adolescent peer group in the formation and maintenance of secondary school institutional culture. Discourse: Studies in the Cultural Politics of Education, 25(3), 351-364.

Brown, B. B. (1989). Social Type Ratings Interview Manual. Retrieved from http://prsg.education.wisc.edu/Measures.html\#m3 on April 20, 2007.

Brown, B. B. (1990). Peer groups and peer cultures. In S. S. Feldman \& G. R. Elliott (Eds.), At the threshold: The developing adolescent (pp. 171-196). Cambridge, MA: Harvard University Press.

Brown, B. B. (1999). Measuring the peer environment of American adolescents. In S. L. Friedman \& T. D. Wachs (Eds.), Assessment of the environment across the lifespan (pp. 59-90). Washington, DC: American Psychological Association.

Brown, B. B., Eicher, S. A., \& Petrie, S. (1986). The importance of peer group (“crowd”) affiliation in adolescence. Journal of Adolescence, 9, 73-96.

Brown, B. B., \& Lohr, M. J. (1987). Peer-group affiliation and adolescent self-esteem: An integration of ego-identity and symbolic-interaction theories. Journal of Personality and Social Psychology, 52, 47-55. 
Brown, B. B., Lohr, M. J., \& Trujillo, C. (1990). Multiple crowds and multiple life styles: Adolescents' perceptions of peer-group stereotypes. In R. E. Muuss (Ed.), Adolescent behavior and society: A book of readings (pp. 30-36). New York: Random House.

Brown, B. B., Mory, M. S., \& Kinney, D. (1994). Casting adolescent crowds in a relational perspective: Caricature, channel and context. In R. Montemayor, G. R. Adams, T. P. Gulotta (Eds.), Personal relationships during adolescence (pp. 123-167). Thousand Oaks, CA: Sage.

Brown, B. B., Mounts, N., Lamborn, S. D., \& Steinberg, L. (1993). Parenting practices and peer group affiliation. Child Development, 64, 467-482.

Buff, S. A. (1970). Greasers, dupers and hippies: Three responses to the adult world. In L. Howe (Ed.) The White majority, (pp. 60-77). New York: Random House.

Clasen, D. R., \& Brown, B. B. (1985). The multidimensionality of peer pressure in adolescence. Journal of Youth and Adolescence, 14(6), 451-468.

Cohen, J. (1979). High school subcultures and the adult world. Adolescence, 55, 491-502.

Coleman, J. C. (1974). Relationships in adolescence. London: Routledge.

Coleman, J. S. (1961). The adolescent society. New York: Free Press.

Corsaro, W. A., \& Eder, D. (1990). Children's peer cultures. Annual Review of Sociology, 16, $197-220$.

Cross, J. R. (2008). The influence of family and peer socialization on adolescent beliefs about intergroup relations. Unpublished doctoral dissertation, Ball State University, Muncie, IN. 
Delsing, M. J. M. H., ter Bogt, T. F. M., Engels, R. C. M. E., \& Meeus, W. H. J. (2007). Adolescents' peer crowd identification in the Netherlands: Structure and associations with problem behaviors. Journal of Research on Adolescents, 17(2), 467-480.

Dolcini, M. M., \& Adler, N. E. (1994). Perceived competencies, peer group affiliation, and risk behavior among early adolescents. Health Psychology 13(6), 496-506.

Downs, W. R., \& Rose, S. R. (1991). The relationship of adolescent peer groups to the incidence of psychosocial problems. Adolescence, 26, online version retrieved 4/13/07.

Dunphy, D. C. (1969). Cliques, crowds, and gangs. Melbourne, Australia: Cheshire.

Durbin, D. L., Darling, N., Steinberg, L., \& Brown, B. B. (1993). Parenting style and peer group membership among European-American adolescents. Journal of Research on Adolescence, 3(1), 87-100.

Eccles, J. S., \& Barber, B. L. (1999). Student council, yolunteering, basketball, or marching band: What kind of extracurricular involvement matters? Journal of Adolescent Research, 14(1), 10-43.

Eckert, P. (1989). Jocks \& Burnouts: Social categories and identity in the high school. New York: Teachers College.

Eder, D. (1985). The cycle of popularity: Interpersonal relations among female adolescents. Sociology of Education, 58, 154-165.

England, E. M,, \& Petro, K. D. (1998). Middle school students' perceptions of peer groups: Relative judgments about group characteristics. Journal of Early Adolescence, 18(4), 349-373.

Erikson, E. H. (1968). Identity, youth, and crisis. New York: Norton. 
Foucault, M. (1970). The order of things: An archaeology of the human sciences. New York: Pantheon. (Original work published 1966)

Friesen, D. (1968). Academic-Athletic-Popularity syndrome in the Canadian high school society. Adolescence, 3, 39-52.

Gall, M. D., Gall, J. P., \& Borg, W. R. (2003). Educational research: An introduction. Boston: Allyn \& Bacon.

Garner, R., Bootcheck, J., Lorr, M., \& Rauch, K. (2006). The adolescent society revisited: Cultures, crowds, climates and status structures in seven secondary schools. Journal of Youth and Adolescence, 35(6), 1023-1035.

Gavin, L. A., \& Furman, W. (1989). Age differences in adolescents' perceptions of their peer groups. Developmental Psychology, 25, 827-834.

Giorgi, A. (1970). Psychology as a human science: A phenomenological approach. New York: Harper \& Row.

Hartmann, D. P., \& Pelzel, K. E. (2005) Design, measurement, and analysis in developmental research. In M. E. Lamb \& M.H. Bornstein (Eds.) Developmental science: An advanced textbook (5 ${ }^{\text {th }}$ ed.) (pp. 103-184). Mahwah, NJ: Lawrence Erlbaum.

Heaven, P. C. L., Ciarrochi, J., Vialle, W. (2008). Self-nominated peer crowds, school achievement, and psychological adjustment in adolescents: A longitudinal analysis. Personality and Individual Differences, 44, 977-988.

Heaven, P. C. L., Ciarrochi, J., Vialle, W., \& Cechavicuite, I. (2005). Adolescent peer crowd self-identification, attributional style and perceptions of parenting. Journal of Community \& Applied Social Psychology, 15, 313-318. 
Hollingshead, A. B. (1975). Elmtown's Youth and Elmtown Revisited (rev. ed.) New York: John Wiley \& Sons.

Husserl, E. (1962). Cartesian meditations (D. Cairns, Trans.). The Hague: Matius Nijhof.

Johnson, J. A. (1987). Influence of adolescent social crowds on the development of vocational identity. Journal of Vocational Behavior, 31, 182-199.

Kahn, C. M. (1989). Family relationships and friendships in adolescence: Continuities and discontinuities. Unpublished doctoral dissertation, Department of Psychology, The Catholic University of America.

Kinney, David A. (1990). Dweebs, headbangers and trendies: Adolescent identity formation and change within socio-cultural contexts. Unpublished doctoral dissertation, Indiana University, Bloomington.

Kinney, D. A. (1993). From nerds to normals: The recovery of identity among adolescents from middle school to high school. Sociology of Education, 66, 21-40.

Kinney, D. A. (1999). From "headbangers" to "hippies": Delineating adolescents' active attempts to form an alternative peer culture. New Directions for Child and Adolescent Development, 84, 21-35,

La Greca, A. M., \& Harrison, H. M. (2005). Adolescent peer relations, friendships, and romantic relationships: Do they predict social anxiety and depression? Journal of Clinical Child and Adolescent Psychology, 34, 49-61.

La Greca, A. M., Prinstein, M. J., \& Fetter, M. D. (2001). Adolescent peer crowd affiliation: Linkages with health-risk behaviors and close friendships. Journal of Pediatric Psychology, 26(3), 131-143.

Larkin, R. W. (1979) Suburban youth in cultural crisis. New York: Oxford University Press. 
McFarland, D., \& Pals, H. (2005). Motives and contexts of identity change: A case for network effects. Social Psychology Quarterly, 68(4), 289-315.

Merten, D. E. (1996a). Visibility and vulnerability: Responses to rejection by nonaggressive junior high school boys. Journal of Early Adolescence, 16(1), 5-26.

Merten, D. E. (1996b). Information versus meaning: Toward a further understanding of early adolescent rejection. Journal of Early Adolescence, 16(1), 37-45.

Messick, D. M., \& Mackie, D. M. (1989). Intergroup relations. Annual Review of Psychology, $40,45-81$.

Mosbach, P., \& Leventhal, H. (1988). Peer group identification and smoking: Implications for intervention. Journal of Abnormal Psychology, 97, 238-245.

Rigsby, L. C., \& McDill, E. L. (1975). Value orientations of high school students. In H. R. Stub (Ed.), The sociology of education: A sourcebook (pp. 53-75). Homewood, IL: Dorsey.

Rosch, E., \& Lloyd, B. (Eds.) (1978). Cognition and categorization. Hillsdale, NJ: Erlbaum.

Roth, W. D., \& Mehta, J. D. (2002). The Rashomon effect: Combining positivist and interpretivist approaches in the analysis of contested events. Sociological Methods \& Research, 31(2), 131-173.

Schwendinger, H., \& Schwendinger, J. R. (1985). Adolescent subcultures and delinquency. New York: Praeger.

Schwendinger, H., \& Schwendinger, J. R. (1997). Charting subcultures at a frontier of knowledge. British Journal of Sociology, 48(1), 71-94.

Steinberg, L. D. (2005). Adolescence. New York: McGraw-Hill. 
Stone, M. R., \& Brown, B. B. (1998). In the eye of the beholder: Adolescents' perceptions of peer crowd stereotypes. In R. Muuss (Ed.), Adolescent behavior and society: A book of readings (5th ed.; pp. 158-169). Boston : McGraw-Hill.

Stone, M. R., \& Brown, B. B. (1999). Identity claims and projections: Descriptions of self and crowds in secondary school. New Directions for Child and Adolescent Development, 84, 7-20.

Strouse, D. L. (1999). Adolescent crowd orientations: A social and temporal analysis. New Directions for Child and Adolescent Development, 84, 37-54.

Sussman, S., Dent, C. W., \& McCullar, W. J. (2000). Group self-identification as a prospective predictor of drug use and violence in high-risk youth. Psychology of Addictive Behaviors, 14(2), 192-196.

Sussman, S., Pokhrel, P., Ashmore, R. D., \& Brown, B. B. (2007). Adolescent peer group identification and characteristics: A review of the literature. Addictive Behaviors, 32, $1602-1627$.

Urberg, K. A. (1992). Locus of peer influence: Social crowd and best friend. Journal of Youth and Adolescence, 21(4), 439-450.

Urberg, K. A., Degirmencioğlu, S. M., Tolson, J. M., \& Halliday-Scher, K. (1995). The structure of adolescent peer networks. Developmental Psychology, 31(4), 540-547.

Urberg, K. A., Değirmencioğlu, S. M., Tolson, J. M., \& Halliday-Scher, K. (2000). Adolescent social crowds: Measurement and relationship to friendships. Journal of Adolescent Research, 15(4), 427-445. 
Varenne, H. (1982). Jocks and freaks: The symbolic structure of the expression of social interaction among American senior high school students. In G. Spindler (Ed.), Doing the ethnography of schooling (pp. 210-235). New York: Rinehart and Winston.

Vérroneau, M.-H., \& Vitaro, F. (2007). Social experiences with peers and high school graduation: A review of theoretical and empirical research. Educational Psychology, $27(3), 419-445$.

Youniss, J., McLellan, J. A., \& Mazer, B. (2001). Voluntary service, peer group orientation, and civic engagement. Journal of Adolescent Research, 16(5), 456-468.

Youniss, J., McLellan, J. A., \& Strouse, D. (1994). "We're popular, but we're not snobs": Adolescents describe their crowds. In R. Montemayor, G. R. Adams, \& T. P. Gulotta (Eds.), Personal relationships during adolescence (pp. 101-122). Thousand Oaks, CA: Sage. 
Table 1. Definitions in Adolescent Crowd Research Studies

\begin{tabular}{|c|c|c|}
\hline Study & Methodology & Crowd Definition \\
\hline $\begin{array}{l}\text { Hollingshead, } \\
1975\end{array}$ & $\begin{array}{l}\text { Social-Type Rating (without } \\
\text { procedures) }\end{array}$ & "reputational categories" (p. 164) \\
\hline $\begin{array}{l}\text { Schwendinger \& } \\
\text { Schwendinger, } \\
1985,1997\end{array}$ & Social-Type Rating & $\begin{array}{l}\text { “...We call ...these labels [e.g., socialites, preppies, jocks, greasers, kickers, } \\
\text { homeboys, vatos, druggies] 'social-type metaphors' because their meanings, } \\
\text { among other things, signify social regularities in personal behavior.” (p. 72) }\end{array}$ \\
\hline $\begin{array}{l}\text { Clasen \& Brown, } \\
1985\end{array}$ & Social-Type Rating & $\begin{array}{l}\text { "the adolescent social world is comprised of an array of peer groups, or "crowds,' } \\
\text { that vary substantially in normative attitudes, interests, and behaviors" (p. 453) }\end{array}$ \\
\hline $\begin{array}{l}\text { Brown, Eicher, \& } \\
\text { Petrie, } 1986\end{array}$ & Social-Type Rating & $\begin{array}{l}\text { "school- or neighborhood-based collectives commonly referred to as peer groups } \\
\text { or "crowds"” (p. 73) }\end{array}$ \\
\hline $\begin{array}{l}\text { Brown \& Lohr, } \\
1987\end{array}$ & Social-Type Rating & $\begin{array}{l}\text { "the set of large, relatively amorphous groups or 'crowds' that appear at the } \\
\text { beginning of the teenage years" (p. 47) }\end{array}$ \\
\hline $\begin{array}{l}\text { Brown, Mounts, } \\
\text { Lamborn, \& } \\
\text { Steinberg, } 1993\end{array}$ & Social-Type Rating & $\begin{array}{l}\text { "adolescents ... are 'selected into' a particular crowd by virtue of the reputation } \\
\text { they establish among their peers (Brown, 1990)" (p. 468) }\end{array}$ \\
\hline $\begin{array}{l}\text { Brown, Mory \& } \\
\text { Kinney, } 1994\end{array}$ & Social-Type Rating & $\begin{array}{l}\text { "Crowds refer to collections of adolescents identified by the interests, attitudes, } \\
\text { abilities, and/or personal characteristics they have in common." (p. 123) }\end{array}$ \\
\hline $\begin{array}{l}\text { Dolcini \& Adler, } \\
1994\end{array}$ & Social-Type Rating & $\begin{array}{l}\text { "emerge during early adolescence and tend to be larger and more loosely } \\
\text { organized than cliques... typically about one third of students are not identified as } \\
\text { crowd members." (pp. 496-497) }\end{array}$ \\
\hline $\begin{array}{l}\text { Stone \& Brown, } \\
1998\end{array}$ & $\begin{array}{l}\text { Social-Type Rating } \\
\text { Study 1: Describing characteristics of } \\
\text { crowds } \\
\text { Study 2: Social-Type Rating with peer } \\
\text { nomination into named crowds }\end{array}$ & $\begin{array}{l}\text { Study 1: "six domains commonly used to characterize crowds: dress and } \\
\text { grooming styles; sociability (the way members related to students outside their } \\
\text { group); academic attitudes (how students felt about school achievement and } \\
\text { learning); the crowd's hangout at school; typical weekend activities; and } \\
\text { participation in five types of school-sponsored extracurricular activities" (p. 159). }\end{array}$ \\
\hline $\begin{array}{l}\text { Stone \& Brown, } \\
1999\end{array}$ & $\begin{array}{l}\text { Social-Type Rating \& Group by } \\
\text { behaviors } \\
\text { "Respondents' identification with each } \\
\text { crowd was computed as the number of } \\
\text { matches between an individual's self- } \\
\text { description and the description of that } \\
\text { crowd in the domains of dress and }\end{array}$ & "reputation-based abstract social categories" (p. 7) \\
\hline
\end{tabular}




\begin{tabular}{|c|c|c|}
\hline & $\begin{array}{l}\text { grooming, behavior toward people not } \\
\text { in their own crowd, weekend activities, } \\
\text { and relations with teachers" (p. 11) }\end{array}$ & \\
\hline $\begin{array}{l}\text { Urberg, } \\
\text { Değirmencioğlu, } \\
\text { Tolson, \& } \\
\text { Halliday-Scher, } \\
2000\end{array}$ & $\begin{array}{l}\text { Social-Type Rating \& Self- } \\
\text { identification } \\
\text { "the social crowd most of your } \\
\text { classmates would say you belong to } \\
\text { now" (p. 432) chosen from list of } 8 \text { (no } \\
\text { multiples allowed) }\end{array}$ & $\begin{array}{l}\text { "a group of people who act in the same way or do the same sorts of things, } \\
\text { whether or not they hang out together" (p. 431) }\end{array}$ \\
\hline Johnson, 1987 & $\begin{array}{l}\text { Self-identification } \\
\text { Social Crowd Membership } \\
\text { questionnaire with list of crowd names } \\
\text { from interviews }\end{array}$ & Simply "adolescent social crowds." \\
\hline $\begin{array}{l}\text { Mosbach \& } \\
\text { Leventhal, } 1988\end{array}$ & $\begin{array}{l}\text { Self-identification } \\
\text { "With which group do you most enjoy } \\
\text { doing things?" (p. 239) }\end{array}$ & $\begin{array}{l}\text { "We would like to know what sorts of groups or types of people there are in this } \\
\text { school. I mean groups like freaks and jocks. Can you tell me what the different } \\
\text { groups are?"(p. 239) }\end{array}$ \\
\hline Urberg, 1992 & $\begin{array}{l}\text { Self-identification } \\
\text { "The subject was asked to check the } \\
\text { crowd that most people would think that } \\
\text { he or she belonged to." (p. } 443 \text { ) }\end{array}$ & $\begin{array}{l}\text { "social crowd [is] an aspect of the peer network....some crowds may be both } \\
\text { interaction and reputation based." (p. 440) }\end{array}$ \\
\hline $\begin{array}{l}\text { Durbin, Darling, } \\
\text { Steinberg \& } \\
\text { Brown, } 1993\end{array}$ & $\begin{array}{l}\text { Self-identification } \\
\text { "a) the crowd to which most of their } \\
\text { classmates would say they belonged; b) } \\
\text { the crowd to which most of their } \\
\text { classmates would say most of their } \\
\text { friends belonged; and c) the crowd to } \\
\text { which they would like to belong if they } \\
\text { could." (p. 92) }\end{array}$ & $\begin{array}{l}\text { "In this study, crowds were defined as reputation-based groups of peers that were } \\
\text { both formed and governed by the adolescents themselves (Brown, 1990)." (p. 88) }\end{array}$ \\
\hline $\begin{array}{l}\text { Urberg, } \\
\text { Değirmencioğlu, } \\
\text { Tolson, \& } \\
\text { Halliday-Scher, } \\
1995\end{array}$ & $\begin{array}{l}\text { Self-identification } \\
\text { Also social-cognitive map (using } \\
\text { NEGOPY) }\end{array}$ & $\begin{array}{l}\text { Students were asked which crowd from a list generated from student interviews } \\
\text { "most people would say they belong to" (p. 542) }\end{array}$ \\
\hline $\begin{array}{l}\text { Eccles \& Barber, } \\
1999\end{array}$ & $\begin{array}{l}\text { Self-identification } \\
\text { "We asked the participants to indicate } \\
\text { which of five characters [from the }\end{array}$ & $\begin{array}{l}\text { "As one moves into and through adolescence, individuals become identified with } \\
\text { particular groups of friends or crowds" (p. 29) }\end{array}$ \\
\hline
\end{tabular}




\begin{tabular}{|c|c|c|}
\hline & $\begin{array}{l}\text { movie The Breakfast Club] (the } \\
\text { Princess, the Jock, the Brain, the Basket } \\
\text { Case, or the Criminal) was most like } \\
\text { them. We told them to ignore the sex of } \\
\text { the character and base their selection on } \\
\text { the type of person each character was." } \\
\text { (p. 30) }\end{array}$ & \\
\hline $\begin{array}{l}\text { Sussman, Dent, } \\
\text { McCullar, } 2000\end{array}$ & $\begin{array}{l}\text { Self-identification } \\
\text { "People often hang out in different } \\
\text { groups at school. Circle the letter of the } \\
\text { one group that you feel that you're most } \\
\text { a part of." (p. 193) }\end{array}$ & "Youth give names to the peer groups with which they identify" (p. 192) \\
\hline $\begin{array}{l}\text { La Greca, } \\
\text { Prinstein, \& } \\
\text { Fetter, } 2001\end{array}$ & $\begin{array}{l}\text { Self-identification } \\
\text { Peer Crowd Questionnaire "picked the } \\
\text { crowd with which they most identified" } \\
\text { (p. 134) }\end{array}$ & $\begin{array}{l}\text { "Crowds are reputation-based groups of teens who may or may not spend large } \\
\text { amounts of time together (Brown, 1989)." (p. 132) }\end{array}$ \\
\hline $\begin{array}{l}\text { Barber, Eccles, \& } \\
\text { Stone, } 2001\end{array}$ & $\begin{array}{l}\text { Self-identification } \\
\text { "We asked the participants to indicate } \\
\text { which of five characters [from the } \\
\text { movie The Breakfast Club] (the } \\
\text { Princess, the Jock, the Brain, the Basket } \\
\text { Case, or the Criminal) was most like } \\
\text { them. We told them to ignore the } \\
\text { gender of the character and base their } \\
\text { selection on the type of person each } \\
\text { character was." (p. 432) }\end{array}$ & $\begin{array}{l}\text { "Brown and colleagues have suggested that adolescents develop socially } \\
\text { construed representations of their peers' identities, or 'crowd' identities, which } \\
\text { serve not only as pre-existing, symbolic categories ... but also as public identities } \\
\text { for themselves..." (p. 431) }\end{array}$ \\
\hline $\begin{array}{l}\text { Heaven, } \\
\text { Ciarrochi, Vialle, } \\
\text { Cechavicuite, } \\
2005\end{array}$ & $\begin{array}{l}\text { Self-identification } \\
\text { Indicate the 'kind of students you hang } \\
\text { around with' by selecting one group } \\
\text { from a list of group descriptions: } \\
\text { 'students who study seriously and have } \\
\text { good relations with teachers', 'students } \\
\text { who spend a lot of time playing sports', } \\
\text { 'students who like to party, and } \\
\text { sometimes use alcohol and/or drugs', } \\
\text { 'students who are popular, liked by }\end{array}$ & Voluntary groups (p. 313) \\
\hline
\end{tabular}




\begin{tabular}{|c|c|c|}
\hline & $\begin{array}{l}\text { other students and enjoy participating in } \\
\text { different school activities', 'students } \\
\text { who rebel against teachers and do not } \\
\text { always do homework'. (p. } 315 \text { ) }\end{array}$ & \\
\hline $\begin{array}{l}\text { La Greca \& } \\
\text { Harrison, } 2005\end{array}$ & $\begin{array}{l}\text { Self-identification } \\
\text { Peer Crowd Questionnaire listed jocks, } \\
\text { burnouts, brains, populars, alternatives, } \\
\text { none/average. "adolescents selected the } \\
\text { crowd with which they most identified." } \\
\text { (p. 52) }\end{array}$ & $\begin{array}{l}\text { "Peer crowds are 'reputation-based collectives of similarly stereotyped } \\
\text { individuals who may or may not spend much time together' (Brown, 1990, p. } \\
\text { 177)." (p. 50) }\end{array}$ \\
\hline $\begin{array}{l}\text { McFarland \& } \\
\text { Pals, } 2005\end{array}$ & $\begin{array}{l}\text { Self-identification } \\
\text { (1) Ideal: "If you could belong to any } \\
\text { crowd, which one would you most want } \\
\text { to be part of?" (if none, write "none") } \\
\text { (2) Actual: "Which crowd would you } \\
\text { personally say that you belong to?" (If } \\
\text { you don't think you belong to any of the } \\
\text { crowds on the list, write "none") } \\
\text { (3) Public: "Write the name of the one } \\
\text { crowd that your classmates would say } \\
\text { you belong to." (p. 294) }\end{array}$ & $\begin{array}{l}\text { "reputational groups with which actors are identified... Therefore, crowd } \\
\text { designations are defined by others and influence individuals by framing their } \\
\text { subsequent behavior." (p. 293) }\end{array}$ \\
\hline Buff, 1970 & $\begin{array}{l}\text { Qualitative Ethnography } \\
\text { Observation }\end{array}$ & $\begin{array}{l}\text { "different categories that young people would use to describe themselves, one } \\
\text { another, and outside groups" (p. 62) }\end{array}$ \\
\hline Larkin, 1979 & $\begin{array}{l}\text { Qualitative Ethnography } \\
\text { Observation, Interview }\end{array}$ & $\begin{array}{l}\text { "The students are organized both formally and informally into a number of } \\
\text { hierarchies resulting in a pluralistic elite structure" (p. 69) }\end{array}$ \\
\hline Varenne, 1982 & $\begin{array}{l}\text { Qualitative Ethnography } \\
\text { Observation, interviews }\end{array}$ & $\begin{array}{l}\text { Refers to crowds as cliques. "A clique was never an immediately apprehensible } \\
\text { reality. Cliques never walked down corridors like phalanxes. They did not have a } \\
\text { sanctioned distinctiveness. All the diacritic marks which students did use to } \\
\text { differentiate between the cliques...could be used by people who did not belong to } \\
\text { the clique which was normally symbolized by a particular pattern of these } \\
\text { markers....students could deny their most obvious clique identification by } \\
\text { emphasizing the fact that particular markers generally associated with another } \\
\text { clique in fact applied to them." (p. 220) }\end{array}$ \\
\hline Eckert, 1989 & $\begin{array}{l}\text { Qualitative } \\
\text { Ethnography }\end{array}$ & $\begin{array}{l}\text { "The Jocks and Burnouts are adolescent embodiments of the middle and working } \\
\text { class respectively; their two separate cultures are in many ways class cultures; and } \\
\text { opposition and conflict between them define and exercise class relations and }\end{array}$ \\
\hline
\end{tabular}




\begin{tabular}{|c|c|c|}
\hline & & $\begin{array}{l}\text { differences. However, they do not exist separately as inward-looking categories, } \\
\text { but in a state of intense mutual awareness and thus of continual mutual influence: } \\
\text { each category defines itself very consciously as what the other is not." (p. 5) }\end{array}$ \\
\hline $\begin{array}{l}\text { Kinney, 1990; } \\
\text { Kinney, 1993; } \\
\text { Kinney, 1999 }\end{array}$ & $\begin{array}{l}\text { Qualitative Ethnography } \\
\text { Based on observation and interview } \\
\text { data }\end{array}$ & $\begin{array}{l}\text { "a social stratification system of peer groups and social categories in American } \\
\text { high schools" }(1999, \text { p. } 21)\end{array}$ \\
\hline $\begin{array}{l}\text { Downs \& Rose, } \\
1991\end{array}$ & $\begin{array}{l}\text { Qualitative } \\
\text { Content analysis of } \\
\text { questionnaire/interview. Students } \\
\text { named and described types of groups in } \\
\text { their school, assigned to groups based } \\
\text { on self-report. }\end{array}$ & Term "crowd" not used; adolescent peer groups. \\
\hline $\begin{array}{l}\text { Youniss, } \\
\text { McLellan, \& } \\
\text { Strouse, } 1994\end{array}$ & $\begin{array}{l}\text { Qualitative } \\
\text { Content analysis of the open-ended } \\
\text { responses to two questions on a survey }\end{array}$ & "categorization schemes adolescents use to define the peer world" (p. 108) \\
\hline Brady, 2004 & $\begin{array}{l}\text { Qualitative } \\
\text { Questionnaire (not described in detail) }\end{array}$ & $\begin{array}{l}\text { "Constructed by students and reinforced by administrators and teaching staff, } \\
\text { these groups form distinctive social orders within their respective institutions." (p. } \\
\text { 356) }\end{array}$ \\
\hline $\begin{array}{l}\text { Garner, } \\
\text { Bootcheck, Lorr, } \\
\& \text { Rauch, } 2006\end{array}$ & $\begin{array}{l}\text { Qualitative } \\
\text { Observation, open-ended survey items, } \\
\text { interview }\end{array}$ & $\begin{array}{l}\text { "Crowds are groupings within a school that are recognized as sharing or adhering } \\
\text { to a particular set of norms and values." (p. 1027) }\end{array}$ \\
\hline Cohen, 1979 & $\begin{array}{l}\text { Group by behaviors } \\
\text { Factor analysis of } 47 \text { variables (e.g., } \\
\text { hours a day spent on homework; dating } \\
\text { frequency) }\end{array}$ & $\begin{array}{l}\text { "Subcultures are identified and their contents described through the factor } \\
\text { analysis of questionnaire data measuring respondents' behavioral traits, attitudes } \\
\text { and values" (p. 493) }\end{array}$ \\
\hline Strouse, 1999 & $\begin{array}{l}\text { Group by behaviors } \\
\text { Applied "cluster analysis to scaled } \\
\text { behavioral/attitudinal items often found } \\
\text { to differentiate peer groups" (p. 40) }\end{array}$ & $\begin{array}{l}\text { "social-type labels attached to students who act the same way or do the same } \\
\text { thing" (p. 37) }\end{array}$ \\
\hline $\begin{array}{l}\text { Youniss, } \\
\text { McLellan, \& } \\
\text { Mazer, 2001 }\end{array}$ & $\begin{array}{l}\text { Group by behaviors } \\
\text { Cluster analysis of reputational group } \\
\text { activities "how important is it for } \\
\text { people with your group's reputation to } \\
\text { do the following things?" (p. 461; e.g., } \\
\text { studying, being popular, etc.) }\end{array}$ & $\begin{array}{l}\text { "we conducted a classificatory analysis intended to group students in the present } \\
\text { study according to commonalities in the activities and attitudes of their peer } \\
\text { crowds" (p. } 461 \text { ) }\end{array}$ \\
\hline Brown, Lohr \& & About crowds & "a label attached to students who act the same way or do the same things, whether \\
\hline
\end{tabular}




\begin{tabular}{|l|l|l|}
\hline Trujillo, 1990 & \multicolumn{1}{|c|}{ or not they hang around with each other" (p. 33) } \\
\hline 1998 & $\begin{array}{l}\text { About crowds } \\
\text { Subjects named the types, then were } \\
\text { asked "Write in the space things which } \\
\text { make the students in that group } \\
\text { different from students in other groups. } \\
\text { For example, you might describe the } \\
\text { things typical members of the group do, } \\
\text { the way they look, the kinds of clothes } \\
\text { dhey wear that are different from other } \\
\text { judgments about people we do not know. While we usually don't use these type } \\
\text { ideas once we get to know an individual person, people often do have an } \\
\text { outstanding feature that can make them fit into a type" (p. 354). }\end{array}$ \\
& $\begin{array}{l}\text { students, how they get along with } \\
\text { others, how they feel about school } \\
\text { work, what classes they like, or how } \\
\text { smart they are." (p. 355). }\end{array}$ & \\
\hline
\end{tabular}

